\title{
The effect of long-term whole-body vibration on muscular performance
}

\author{
Yossef Haleva, ${ }^{1,2 \star}$ Ayelet Dunsky, ${ }^{2}$ Yoav Meckel, ${ }^{2}$ Heinz Kleinöder, ${ }^{1}$ Michael Bar-Eli, ${ }^{2}$ Joachim Mester ${ }^{1}$
}

\begin{abstract}
Introduction: The whole-body vibration (WBV) approach is considered to be a unique training method for physical rehabilitation, injury preventions, and improving physical performance in athlete. The scientific literature about WBV is well documented and presents different vibration protocols, different measurements and, as a consequence - different results. Objectives: To explore the effect of a strengthening program with WBV on several muscular strength variables among physical education students in comparison to a control passive group of students. Methods: Thirty-eight healthy male physical education students were randomly allocated into Vibration Group (VG, n=13) - who underwent strengthening program with WBV and external load, and Control Group (CG, $\mathrm{n}=25$ ), that received no treatment. The study included pre-test assessments, 4-week intervention phase and post-test assessments. During the intervention phase VG performed three training sessions per week that included six sets of 30 sec squats with external loads on a WBV platform. Assessments included maximal muscle strength, power, reactive strength and endurance. Results: Significant improvements were shown in all components among the VG from pre to post-tests $(\mathrm{p}<0.001)$, with no significant change among the CG. Conclusions: A 4-week strengthening program with WBV and medium external load improves different components of strength among healthy physical education students.
\end{abstract}

Keywords: Whole body vibration; Strength; Power; Reactive strength.

\section{Resumo}

O efeito de um programa de fortalecimento que consiste em exercícios de vibração de corpo inteiro no desempenho muscular

Introdução: A técnica de vibração de corpo inteiro (WBV) é considerada como um método de treino único para reabilitação física, prevenção de lesões e melhoria do desempenho físico do atleta. A literatura científica sobre a WBV está bastante documentada e apresenta diferentes protocolos de vibração, diferentes medições e, consequentemente - diferentes resultados. Objetivos: explorar o efeito do programa de fortalecimento com WBV em várias variáveis de força muscular entre os estudantes de educação física, em comparação com um grupo de controlo passivo de estudantes. Métodos: Trinta e oito estudantes de ed-
1. The Institute of Training Science and Sport Informatics. German Sport University Cologne, Germany.

2. The Academic College at Wingate. Wingate Institute, Netanya, Israel.

\section{*Correspondence address:}

The Academic College at Wingate

Wingate Institute 4290200, Israel

E-mail: yossihaleva@gmail.com

ORCID: https://orcid.org/0000-0002-9228-7007

BJHBS, Rio de Janeiro, 2020;19(2):100-107

Received on 26/10/2020. Approved on 08/12/2020.

ucação física saudáveis do sexo masculino foram distribuídos aleatoriamente num Grupo de Vibração (VG, n=13) - os quais foram submetidos a um programa de fortalecimento com WBV e carga externa - e num Grupo de Controlo (CG, n=25) - que não receberam tratamento. O estudo incluiu avaliações pré-teste, fase de intervenção de 4 semanas e avaliações pós-teste. Durante a fase de intervenção, o VG realizou três sessões de treino por semana que incluíram seis séries de agachamentos de 30 segundos com cargas externas numa plataforma WBV. As avaliações incluíram a força muscular máxima, potência, força reativa e resistência. Resultados: Foram apresentadas melhorias significativas em todos os componentes do VG, desde os pré-testes até aos pós-testes ( $\mathrm{p}<0,001$ ), sem qualquer alteração significativa por parte do CG. Conclusões: Um programa de 4 semanas de fortalecimento com WBV e carga externa média melhora diversos elementos de força entre os estudantes de educação física saudáveis.

Descritores: Vibração de corpo inteiro; Força; Potência; Força reativa.

\section{Resumen}

El efecto de un programa de fortalecimiento en el rendimiento muscular que consiste en ejercicios con vibración transmitida en todo el cuerpo

Introducción: El enfoque de la vibración transmitida en todo el cuerpo (VBM) se considera un método de entrenamiento 
único para la rehabilitación física, la prevención de lesiones y la mejora del rendimiento físico en el atleta. La literatura científica sobre la VBM está bien documentada y presenta diferentes protocolos de vibración, diferentes mediciones y, como consecuencia - diferentes resultados. Objetivos: explorar el efecto del programa de fortalecimiento con $\mathrm{VMB}$ en varias variables de fuerza muscular entre los estudiantes de educación física en comparación con un grupo pasivo de referencia de estudiantes. Métodos: Treinta y ocho estudiantes masculinos de educación física sanos fueron asignados al azar en el grupo de Vibración (VG, $n=13$ ) - que se sometieron a un programa de fortalecimiento con VMB y carga externa -, y el Grupo de Referencia (CG, $\mathrm{n}=25$ ) - que no recibió ningún tratamiento. El estudio incluyó evaluaciones previas a la prueba, fase de intervención de 4 sem-

\section{Introduction}

Muscle strength is of primary importance in human life, particularly in elite, amateur, and leisure sport, but also in prevention and rehabilitation training. Among athletes, strength and relevant strength training are preconditions for high performance, thus they are practicing different protocols in order to increase the effectiveness of those strength trainings. Additionally, there is a trend towards shorter training times in modern strength training at different achievement levels. ${ }^{1,2}$

In the last twenty years one of the training approaches, that tries to answer these standards, is based on whole-body vibrations (WBV). This approach is based on a mechanical stimulus generated by motors underneath a platform, which are subsequently transmitted to the human body via feet when standing on the platform. Cardinale and Pope (2003) ${ }^{1}$ defined these mechanical vibrations as deterministic sinusoidal motions in two dimensions: side-to-side alternating and vertical. The effect of $\mathrm{WBV}$ is dependent on the magnitude of the biomechanical loading parameters, such as working time interspersed with rest time, frequency, amplitude and peak acceleration, as well as the positioning of the individual. ${ }^{2}$ The WBV approach with different vibration-producing devices and its effect on humans have been under examination in the training sciences for several years., ${ }^{3}$ It was found to produce neuromuscular adaptation which enhances the tonic vibration reflex that stimulates the muscular reflex for contraction, and improve the function of the neuromuscular systems. ${ }^{5,6}$ When combined with strength training, it provided additional improvements in power and RM1, however, in comparison to maximum voluntary contraction, WBV based on anas y evaluaciones posteriores a la prueba. Durante la fase de intervención, el VG realizó tres sesiones de entrenamiento por semana que incluyeron seis series de sentadillas de 30 segundos con cargas externas en una plataforma WBV.Las evaluaciones incluyeron fuerza muscular máxima, potencia, fuerza reactiva y resistencia. Resultados:Se mostraron mejoras significativas en todos los componentes entre el VG desde el pre y el post test ( $p<0,001$ ), sin cambios significativos entre el CG. Conclusiones: Un programa de fortalecimiento de 4 semanas con VBV y carga externa media, mejora los diferentes componentes de fuerza entre los estudiantes de educación física sanos..

Palabras clave: Vibración transmitida al cuerpo entero; Fuerza; Potencia; Fuerza reactiva.

bodyweight produced lower EMG (electromyogram) activity, thus it was suggested that additional external load must be introduced for further improvements. ${ }^{7-13}$ WBV for long-term had significantly higher improvement on strength and jump performance in comparison to a passive control group, and had small higher effect on those variables compared to a control group performing the same exercise without WBV. ${ }^{14}$ It is important to note that the effects of long-term WBV on muscle strength and power are inconclusive, as different studies report diverse methods, different vibration protocols, and different measurements. ${ }^{15,16}$ Thus, the purpose of the current study was to explore the effect of strengthening program with WBV on several muscular strength variables among physical education students in comparison to a control passive group of students.

\section{Materials and methods}

\section{Ethics}

The study was performed in consensus with all Helsinki requirements and was conducted with the understanding and the consent of the human subject. The Ethical Committee of the responsible University faculty (German Sport University Cologne) has approved the study.

Inclusion criteria for participating in the study were: 1 ) Registered to the sport university at the time of the study, 2) Training regularly (at least twice a week), and 3) have experience in training with free weights. None of the participants took any prescription medications or food supplements during the study. 
Participants with a previous history of fractures or bone injuries were excluded from the study.

\section{Participants}

Thirty-eight healthy male physical education students volunteered to take part in the study. Their mean age was $24.95 \pm 3.44$ years, mean weight was 79.86 $\pm 9.41 \mathrm{~kg}$, and mean height was $183.14 \pm 7.61 \mathrm{~cm}$. Standard calibrated scales and stadiometers (Seca, 707, Germany) were used to determine body mass and height. The participants were informed of the experimental procedures, and signed an informed consent prior to participation.

\section{Study design}

The study lasted six weeks. On the first week participant partook in two pre-testing assessments, followed by four weeks of intervention phase, and one week in which they partook in two post-testing assessments. Using a controlled study design, participants were randomly assigned to one of two study groups, after matching for strength assessments according to the pre-test assessments: ${ }^{14}$ Vibration Group (VG) - performed WBV during the intervention phase $(n=13)$-, and Control Group (CG), that kept their physical activity routine (as physical education students) with no specific program during the intervention period $(n=25)$. Participants were asked to avoid any additional physical activity during the study (other than the study program). During the study 16 participants dropout due to missed follow-up tests, injuries, or absence from more than $10 \%$ of the training sessions. Out of these 16, 10 participants from the CG were excluded as they did not keep their physical activity routine and added different training methods during the study period.

Thus, only 22 participants were included in the final analysis: 12 in VG and 10 in CG.

\section{Training protocol}

During the 4-week intervention phase, participants in the VG performed three training sessions per week, with a minimum of 48 hours between sessions. All training sessions were performed at a gym with sportswear and sneakers, during morning hours (2-3 hours after breakfast), with an average air temperature of about $18-22^{\circ} \mathrm{C}$. Participants were instructed to drink 500cc of water $30 \mathrm{~min}$ before each training session. The training protocol was based on traditional strength training method ${ }^{17}$ with additional vibration loads. Each training session lasted approximately 40-50 min, beginning with a standard warm-up, followed by the training phase, and a recovery phase. The training phase was composed of six sets of $30 \mathrm{sec}$ exercise and one-minute rest of dynamic squats in shoulder-width apart (between 10-12 repetitions) with external loads using a special barbell (the hands could touch the support handle of the device lightly, in order to maintain stability), whilestanding on WBV platform (Power Plate $\subset$ ) with constant vibration amplitudes in a vertical direction, at $4 \mathrm{~mm}$. The external load was adjusted to $40 \%$ of 1RM (that was based on a Maximum strength evaluation that was measured prior training phase), that is considered a medium training intensity for athletes. ${ }^{18}$ Additionally, the frequency of the vibrations was constant during the training session and increased from 30 to $40 \mathrm{~Hz}$ after every four sessions. It should be noted that during the training session a supervision was always present. Table 1 presents the training progress over the 6-week program.

\section{Strength Assessments}

Based on the Bührle's (1989) model ${ }^{19}$ the strength components that were measured in the current study were: isomeric maximal strength, power, reactive

Table 1. The Training Protocol Sessions for the experimental/Vibrations Group

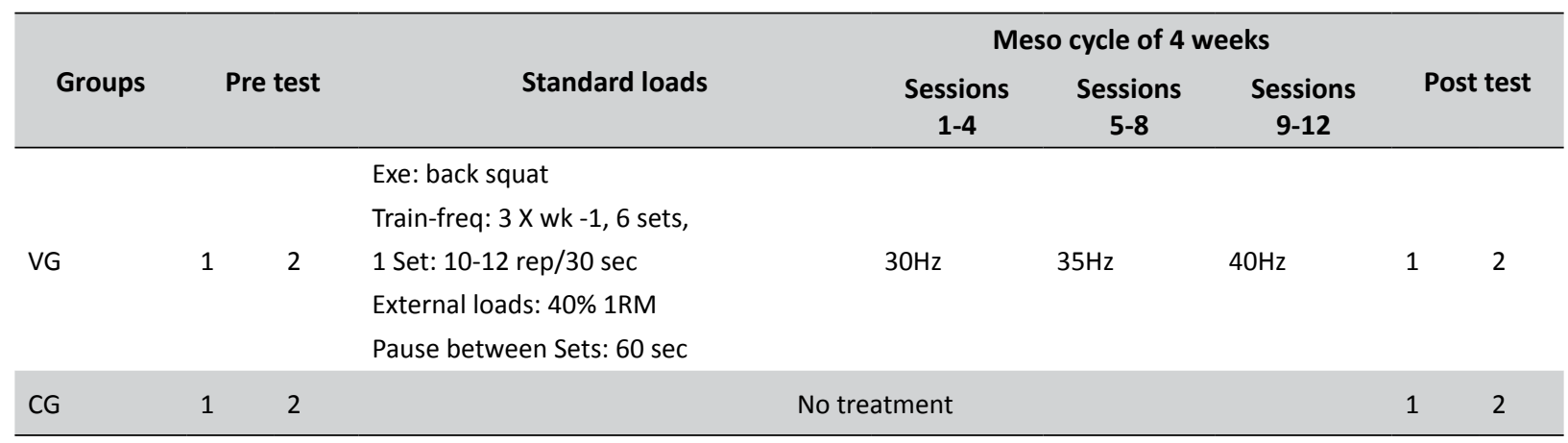

Legend: VG = WBV group; $C G$ = control group; Train-freq = training frequency; Exe = Exercise. 
strength, and muscular endurance. Accordingly, pre- and post-training assessments included the following tests:

Maximal isomeric strength - It was measured by Static leg press on the isokinetic "Desmotronic" Function, which was performed in an upright sitting position (seat-back angle $85^{\circ}$ ), with knee angle at $120^{\circ}$.During threesuccessive measurements (with 30-60 s break) the participant had to produce maximum static contraction against rigid resistance. The measuring period of individual attempts lasted up to $5 \mathrm{~s}$.

Power assessment - It was measured by Squat Jump (SJ) - a vertical jump performed from a squatting position (knee angle $90^{\circ}$ ) with feet at approximately hip width, and without swinging the arms. Each participant performed three SJ with a 1-min break in between. After each jump participants received feedback about jump height $(\mathrm{cm})$ and jump technique. The highest achievement was used for analysis.

Reactive strength assessment - It was measured by Counter Movement Jump (CMJ) and Drop Jump (DJ). CMJ is performed like the SJ with a "dip" just prior the vertical jump, thus momentarily stretching the involved muscles (long S.C.C according to Young et al. 1999) ${ }^{20}$ and producing a more powerful movement. Each participant performed three CMJ with a 1-min break in between. After each jump, participants received feedback about jump height $(\mathrm{cm})$ and jump technique. The highest achievement was used for analysis. During DJ participants dropped from a box $40 \mathrm{~cm}$ high and upon landing, they were instructed to jump for maximum vertical height and minimum ground contact time. Height jump (cm), contact time (ms), and height/contact time $\left(\mathrm{cm}^{*} \mathrm{~s}-1\right)$ were immediately displayed on the computer screen, and feedback was provided after each trial. This was considered important so that subjects could determine the optimum combination of height and contact time to produce the best height/ contact time ratio. The best height/time score for each DJ was used for analysis. Due to the relatively short contact time and the need to quickly shift from the eccentric phase to the concentric phase, this test is considered a measure of reactive strength (short S.C.C) of leg capacity. ${ }^{20,21}$

Maximum strength evaluation (10RM) - This test was obtained by knee extensions (the distance between bench and ground was to $52 \mathrm{~cm}$, with the aim that all participants perform the same range) with a special barbell with angled iron strips. Additional load was then increased every 2 min up to individual maximum. Maximum strength with additional load was regarded as the load at which 10RM could be performed. The goal was to determine maximum efficiency of trunk and leg musculature, in order to subsequently adjust the additional load for training.

Muscular endurance assessment - It was measured based on the Maximum strength evaluation (10RM), in which, $40 \%$ of 1RM was calculated. ${ }^{22}$ Participants performed the strength endurance test - maximum repetition number of knee extensions that they could perform with $40 \%$ of 1RM.

Each assessment session began with a warm-up that was divided into a 5-min general and 5-min of specific warm-up for the respective jumps (SJ, CMJ and DJ). Subsequently, participants performed 5-min flexibility exercises.

During each two assessment timepoints all tests were performed but the Muscular Endurance Assessment that was not performed during Pre-test 1, and Post-test 1 assessments, and the 10RM that was not performed during Pre-test-2, and Post-test-2 assessments.

\section{Statistical analysis}

The assumptions of the current study were that the strengthening program consisting exercise with WBV will improve muscular strength in comparison to the passive control group that will have no change in the assessed variables. Data were subjected to analysis of variance (One-way ANOVA) followed by the Tukey's posthoc test (using the program SPSS 25 statistical computer program). Differences between groups were considered significant at a level of $\mathrm{p} \leq 0.05$ for all comparisons.

\section{Results}

\section{Pre-test assessments}

There were no differences in any of the strength assessments achievements between the groups, prior the training phase $(\mathrm{p}>0.05)$.

\section{Post-test assessments}

Changes in strength performances following the training program of VG are presented in Table 2 and 


\section{Original article}

Figure 1. As it can be seen in Table 2, all strength components improved significantly from pre-test to posttest among the VG $(\mathrm{p}<0.001)$, but not among the CG (Table 2). More specifically, at the SJ test, the VG had significant $17.7 \%$ improvement $(\mathrm{p}<0.001)$ with no significant change among CG. Additionally, significant groups X time interaction was found (F1, 20=32.94, $\mathrm{p}<0.001)$. At the CMJ test, the VG had significant $11.66 \%$ improvement $(\mathrm{p}<0.001)$ with no significant change among CG. At the DJ, test the VG had significant $16.53 \%$ improvement $(\mathrm{p}<0.01)$ with no significant change among CG. Additionally, significant groups $\mathrm{X}$ time interaction was found $(\mathrm{F} 1,20=5.05$, $\mathrm{p}<0.05)$. At the Maximum strength test, the VG had significant $14.74 \%$

Figure 1. Changes on strength performance among the VG versus CG following the intervention phase

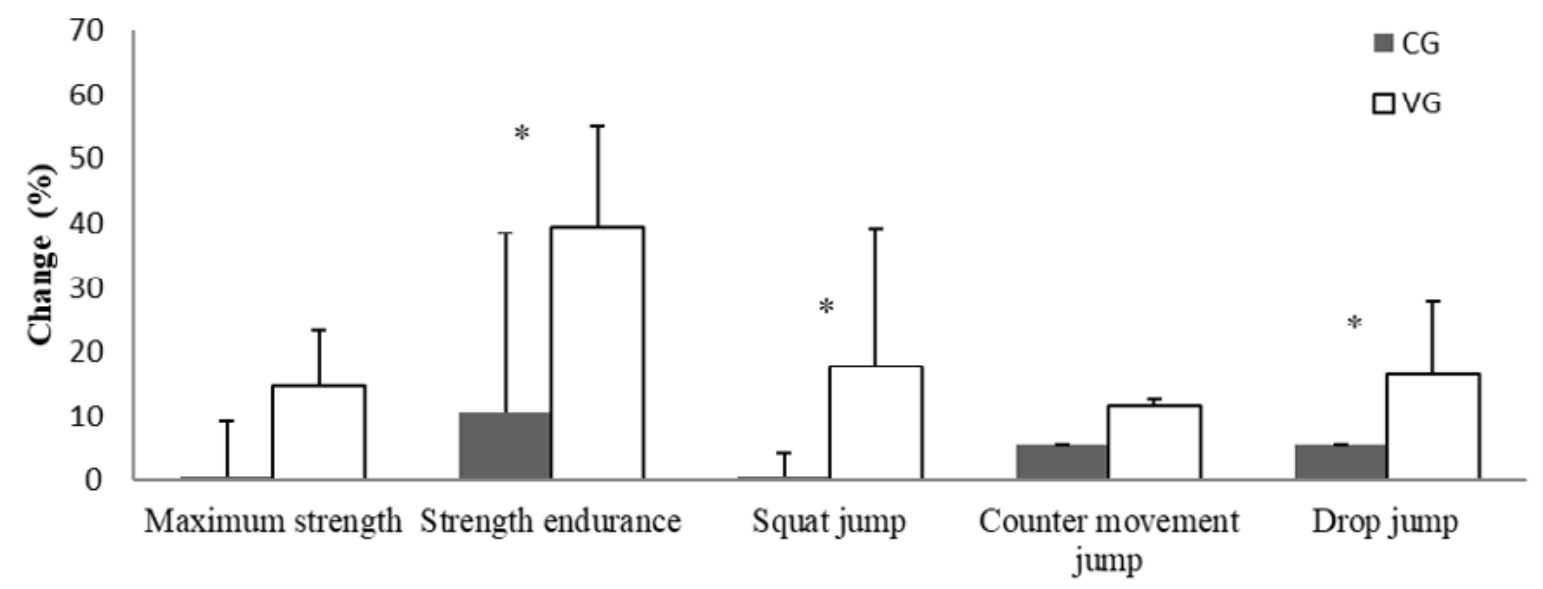

* Significant differences between groups $(p<0.01)$.

Table 2. Changes in strength components among VG versus CG (means \pm SD)

\begin{tabular}{|c|c|c|c|c|c|c|c|c|c|c|}
\hline \multirow{2}{*}{ Variable } & \multicolumn{3}{|c|}{$\begin{array}{c}\text { Vibration Group } \\
\text { (VG) N=12 }\end{array}$} & \multicolumn{3}{|c|}{$\begin{array}{l}\text { Control Group } \\
\text { (CG) } \mathbf{N}=10\end{array}$} & \multirow{2}{*}{$\begin{array}{c}\text { time } \\
\text { F }(\mathbf{1}, \mathbf{2 0})\end{array}$} & \multirow{2}{*}{$\mathbf{p}$} & \multirow{2}{*}{$\begin{array}{l}\text { time*- } \\
\text { group } \\
\text { F }(\mathbf{1}, 20)\end{array}$} & \multirow{2}{*}{$\mathbf{p}$} \\
\hline & Pre & Post & ES & Pre & Post & ES & & & & \\
\hline $\begin{array}{l}\text { Maximal } \\
\text { Strength [N] }\end{array}$ & $\begin{array}{l}4439.20 \pm \\
1058.43\end{array}$ & $\begin{array}{l}5093.60 \pm \\
1149.15^{*}\end{array}$ & 0.62 & $\begin{array}{l}5031.50 \pm \\
837.35\end{array}$ & $\begin{array}{l}5058.30 \pm \\
879.46\end{array}$ & 0.03 & 3.31 & 0.09 & 2.81 & 0.11 \\
\hline $\begin{array}{l}\text { Maximal Repe- } \\
\text { tition Number } \\
{[\mathrm{t}]}\end{array}$ & $\begin{array}{l}27.82 \pm \\
9.58\end{array}$ & $\begin{array}{l}38.82 \pm \\
11.05^{* *}\end{array}$ & 1.15 & $\begin{array}{l}25.00 \pm \\
11.38\end{array}$ & $\begin{array}{l}27.6 \pm \\
11.58\end{array}$ & 0.23 & 15.46 & 0.001 & 5.90 & $0.03^{*}$ \\
\hline $\begin{array}{l}\text { Squat Jump } \\
{[\mathrm{cm}]}\end{array}$ & $\begin{array}{l}38.70 \pm \\
4.68\end{array}$ & $\begin{array}{l}45.56 \pm \\
3.68 * *\end{array}$ & 1.47 & $\begin{array}{l}36.74 \pm \\
6.33\end{array}$ & $\begin{array}{l}36.91 \pm \\
6.08\end{array}$ & 0.03 & 36.40 & $>0.001$ & 32.94 & $>0.01 * *$ \\
\hline $\begin{array}{l}\text { Counter Mo- } \\
\text { vement Jump } \\
{[\mathrm{cm}]}\end{array}$ & $\begin{array}{l}41.89 \pm \\
4.86\end{array}$ & $\begin{array}{l}46.77 \pm \\
3.62^{* *}\end{array}$ & 1.01 & $\begin{array}{l}38.39 \pm \\
7.04\end{array}$ & $\begin{array}{l}40.59 \pm \\
7.99\end{array}$ & 0.31 & 18.91 & $>0.001$ & 2.69 & 0.12 \\
\hline $\begin{array}{l}\text { Drop Jump } \\
{[\mathrm{cm}]}\end{array}$ & $\begin{array}{l}31.55 \pm \\
4.19\end{array}$ & $\begin{array}{l}36.76 \pm \\
4.66^{* *}\end{array}$ & 1.24 & $\begin{array}{l}29.42 \pm \\
5.60\end{array}$ & $\begin{array}{l}31.08 \pm \\
4.96\end{array}$ & 0.30 & 18.89 & $>0.001$ & 5.05 & $0.04^{*}$ \\
\hline
\end{tabular}

Legend: ES: effect size (Cohen's d).

* Significant differences between groups $(p<0.05)$.

** Significant differences between groups $(p<0.01)$. 
improvement $(\mathrm{p}<0.05)$ with no significant change among CG. And at the Muscular endurance test, the VG had significant $39.54 \%$ improvement $(p<0.01)$ with no significant change among CG. Additionally, significant groups $\mathrm{X}$ time interaction was found (F1, $20=5.90, p<0.05$ ).

\section{Discussion}

The purpose of the current study was to compare the effect of 4 weeks of strengthening program with WBV on strength components of the lower limb among a group of physical education students in comparison to a passive control group (who kept their physical activity routine). The main findings of this study point to the significant improving effect of the strengthening program with WBV approach on strength components among the VG with no significant changes among participants in the CG.

\section{The effect of WBV on power}

The current results are in line with previous results about the effect of long-term WBV on power as represented by SJ achievements. . $^{15,21,23-25}$ Possible explanation for the positive effect of the strengthening program with WBV on power is based on the fact that the SJ is mainly achieved by fast twitch (FT) muscle fibers requitement. ${ }^{26}$ The higher the proportion of FT muscle fibers that are activated in a specific movement, the higher the jump is. In the current study the VG, showed $17.7 \%$ improvement on that measure, suggesting that the mechanical vibration movement during the WBV training produced neuromuscular adaptation to enhance better recruitment of the FT muscle fibers. $5,14,27$ Our results are in contrast to the findings of Spitzenpfeil $(2000)^{28}$ Cochrane (2004) ${ }^{29}$ and Rittweger et al..$^{30,31}$ that reported a decline in performance among the WBV groups. It is possible that differences in the WBV protocols led to the different effects.

\section{The effect of WBV on reactive strength}

Reactive strength is of particular importance for athletes in sports that includes high jumps such as gymnastics, high jump and volleyball. The CMJ and the DJ resemble those skills, and are based on optimal use of the stretch-shortening cycle. ${ }^{20}$ The positive effect of WBV training on those tests found in the current study are in line with several previous studies Torvinen et al. (2002a\&b), ${ }^{27,32}$ Ziegler (2003) ${ }^{25}$ and Ber- schin et al., ${ }^{18}$ who found that strength training with vibration loads were more effective in comparison to traditional training (the same training program without vibration loads) on CMJ performance, and on DJ performance. ${ }^{23,33,34}$ On the contrary, Spitzenpfeil $(2000)^{28}$ found no improvements of DJ following long term WBV training, while Ziegler $(2003)^{25}$ reported a decline of about $4 \%$ in DJ following WBV. DJ performance is based upon the ability to recruit concentric contraction following landing from a drop of 40 $\mathrm{cm}$, and a very short ground contact time, ${ }^{35}$ thus the musculo-neural system has to adjust to changes in direction of contractions very fast. One possible explanation for changes in that ability following WBV training is based upon the possible change it creates in the neural system, ${ }^{5,20,21}$ thus enabling higher jump through improved biomechanical means (better storage of kinetic energy over the flexible muscle component) and neurophysiological means (improved stretch-shortening cycle).

Regarding the results of maximal strength, the current study found significant $14.74 \%$ improvement among the VG following the strengthening program with WBV. Rønnestad (2009) ${ }^{36}$ reported that WBV loading showed improvement in squat 1 repetition maximum (1RM) compared with no vibration in both trained and untrained participants. Such evidence was also suggested in a systematic review from Rehn et al (2006). ${ }^{26}$ As for the effect of WBV on muscular endurance, Güllich and Schmidtbleicher (1999) ${ }^{37}$ suggested that improvements in maximal strength correlate with improvement in endurance, and our results are in accordance with this suggestion. However, no previous study showed improvements in muscular endurance following strengthening program with WBV.

There are several limitations to the current study, the first one is the fact that the CG did not receive any strengthening program. If they did, it could be suggested that the differences found between the groups occurred specifically due to the WBV. Second, the fact that the WBV protocol used in the current study was based certain vibration amplitudes and frequencies. It is possible that changes in these parameters would lead to higher improvements in the assessed variables.

\section{Conclusion}

Based on the results of the current study, we can conclude that a 4-week strengthening program with WBV and medium external load improves differ- 


\section{Original article}

ent components of strength. Future studies should evaluate the effect of the same training protocol in comparison to a same strengthening program without vibrations, and, in comparison, to other amplitudes or frequencies.

\section{Conflict of interest}

The authors declare no conflict of interest.

\section{Acknowledgments}

The researchers would like to express gratitude to the participants who partook in the study and to Efi Haleva who helped throughout the study.

\section{Article highlights}

\section{Research background}

The whole-body vibration (WBV) approach is considered to be a unique training method for physical rehabilitation, injuries prevention, and improving physical performance in athlete.

\section{Research motivation}

The scientific literature about WBV is documented with inconclusive methods, different vibration protocols, different measurements and, as a consequent - different results.

\section{Research objectives}

To explore the effect of strengthening program with WBV on several muscular strength variables

\section{References}

1. Cardinale M, Pope M. The effects of whole body vibration on humans: Dangerous or advantageous? Acta Physiologica Hungarica. 2003;90(3):195-206.

2. Marín P, Rhea M. Effects of vibration training on muscle strength: A meta-analysis. J. Strength Cond. Res. 2010;24(2):548-556.

3. Morel DS, Dionello CdF, Moreira-Marconi E, et al. Relevance of Whole Body Vibration Exercise in Sport: a Short Review With Soccer, Diver and Combat Sport. African J. Tradit. Complement. Altern. Med. 2017;14(s):19-27.

4. Moreira-Marconi E, Moura-Fernandes MC, Teixeira-Silva Y, et al. Whole-body vibration exercises benefit individuals with knee osteoarthritis: a narrative review. Rev. Hosp. Univ. Pedro Ernesto. $2018 ; 17(1): 44-50$. among physical education students in comparison to a control passive group of students.

\section{Research methods}

Thirty-eight healthy male physical education students were randomly allocated into Vibration Group (VG, n=13) - who underwent strengthening program with WBV and external load, and Control Group (CG, $\mathrm{n}=25$ ), that kept their physical activity routine. The study included pre-test assessments, 4-week intervention phase and post-test assessments. During the intervention phase, VG performed three training sessions per week that included six sets of 30 sec squats with external loads on a WBV platform. Assessments included maximal muscle strength, power, reactive strength and endurance.

\section{Research results}

Significant improvements were shown in all components among the VG from pre to post-tests ( $\mathrm{p}<0.001$ ), with no significant change among the CG.

\section{Research conclusions}

A 4-week strengthening program with WBV and medium external load improves different components of strength among healthy physical education students.

\section{Research perspectives}

Future studies should evaluate the effect of the same training protocol in comparison to a same strengthening program without vibrations, and, in comparison, to other amplitudes or frequencies.

5. Bosco C, lacovelli M, Tsarpela O, et al. Hormonal responses to whole-body vibration in men. Eur J Appl Physiol. 2000;81:449454.

6. Torvinen S, Kannus P, Sievänen H, et al. Effect of 8-month vertical whole body vibration on bone, muscle performance, and body balance: A randomized controlled study. J Bone Min. Res. 2003;18(5):876-884.

7. Wilcock IM, Whatman $\mathrm{C}$, Harris $\mathrm{N}$, et al. Vibration training: Could it enhance the strength, power, or speed of athletes? J Strength Cond Res. 2009;23(2):593-603.

8. Goodwill A, Kidgell D. The effects of whole-body vibration on the cross-transfer of strength. Sci. World J. 2012;1-11.

9. Caserotti $P$, Madsen K. Effects of vibration and resistance training on neuromuscular and hormonal measures. Eur J App Physiol. 2006;96:615-625.

10. Preatoni E, Colombo A, Verga M, et al. The effects of whole- 
body vibration in isolation or combined with strength training in female athletes'. J Strength Cond Res. 2012;26(9):2495-2506.

11. Rønnestad BR, Holden G, Samnøy L, et al. Acute effect of whole-body vibration on power, one-repetition maximum, and muscle activation in power lifters. J. Strength Cond. Res. 2012;26(2):531-539.

12. Rosenberger $A B$, Johannes $J$, Schoenau $E$, et al. Changes in muscle cross-sectional area, muscle force, and jump performance during 6 weeks of progressive whole-body vibration combined with progressive, high intensity resistance training. $J$ Musculoskelet Neuronal Interact. 2017;17(2):38-49.

13. Weier A, Kidgell D. Strength training with superimposed whole body vibration does not preferentially modulate cortical plasticity|. Sci World J. 2012;1-9.

14. Nordlund M M, Thorstensson A. A Strength training effects of whole-body vibration? Scand J Med Sci Sports. 2007;17(2):3849.

15. Hamlin MJ, Manimmanakorn A. Long-term effect of whole body vibration training on jump height: Meta-analysis. J Strength Cond Res. 2014;28(6):1739-1750.

16. Wuestefeld A, Fuermaier A B, Bernardo-Filho M, et al. Towards reporting guidelines of research using whole-body vibration as training or treatment regimen in human subjects-A Delphi consensus study. PLoS One 15. 2020;1-24.

17. Ehlenz H, Grosser M, Zimmermann E. Kraftraining: Grundlagen, Methoden, Übungen, Leistungssteuerung, Trainingsprogramme. BLV. 2003.

18. Berschin G, Schmiedeberg I, Sommer HM, et al. Zum einsatz von vibrationskrafttraining als spezifisches schnellkrafttrainingsmittel in sportspielen. Leistungssport. 2003;4:11-13.

19. Bührle M. Maximalkraft-Schnellkraft-Reaktivkraft. Sportwissenschaft. 1989;4:311-325.

20. Young WB, Wilson GJ, Byrne C, et al. A comparison of drop jump training methods: Effects on leg extensor strength qualities and jumping performance massage and rolling massage view project resistance training responses and adaptations view project. Int J Sport Med. 1999;20:295-303.

21. Serge SC, Manuela P, Julien E, et al. Whole-body vibrtation training effects on the physical performance of basketball players. J Strength Cond Res. 2010;24(4):999-1006.

22. Baechle T, Groves B. Weight training instruction: Steps to success. Human Kinetics Pub. 1994.

23. Knauf A. Muskuläre annpassungen des Körpers auf Ganzkörpervibrationen im Krafttraining. DSHS. 1999.
24. Schlumberger A, Salin D, Schmidtbleicher D, et al. Krafttraining unter vibrationseinwirkung. Sportverletzung Sportschaden. 2001;15:1-7.

25. Ziegler J. Einzelfallstudie über den Einfluss eines Vibrationskrafttrainings in der Saisonvorbereitung eines professionellen Eishockeyspielers. DSHS. 2003.

26. Rehn B, Lidström J, Skoglund J, et al. Effects on leg muscular performance from whole-body vibration exercise: A systematic review. Scand J Med Sci Sports. 2006;17(1):2-11.

27. Torvinen $\mathrm{S}$, Kannus $\mathrm{P}$, Sieva $\mathrm{H}$, et al. Effect of four-month vertical whole body vibration on performance and balance. Med Sci Sport Exerc. 2002;34:1523-1528.

28. Spitzenpfeil P. Vibrationsbelastungen im alpinen Skirennlauf: Analyse - Simulation. DSHS. 2000.

29. Cochrane DJ, Legg SJ, Hooker MJ, et al. The short-term effect of whole-body vibration training on vertical jump, sprint, and agility performance. J Strength Cond Res. 2004;18(4):828-832.

30. Rittweger J, Beller G, Felsenberg D, et al. Acute physiological effects of exhaustive whole-body vibration exercise in man. Clin. Physiol. 2000;20(2):134-142.

31. Rittweger J, Mutschelknauss M, Felsenberg D, et al. Acute changes in neuromuscular excitability after exhaustive whole body vibration exercise as compared to exhaustion by squatting exercise. Clin Phy Func Im. 2003;23(2):81-86.

32. Torvinen $\mathrm{S}$, Kannus $\mathrm{P}$, Sievähen $\mathrm{H}$, et al. Effect of four-month vertical whole body vibration on performance and balance. Physical Fitness and Performance. 2002;1523-1528.

33. Kube J. Die einsetzbarkeit und wirkung von vibrationskraftraining in verbindung mit konventionellen methoden der kraft- und schnellkraftentwicklung innerhalb einer vorbereitungsperiode im kurzsprint. DSHS. 2002.

34. Mahieu NN, Witvrouw E, Van De Voorde D, et al. Improving strength and postural control in young skiers: whole-body vibration versus equivalent resistance training. J Ath Train. 2006;41(3):286-293.

35. Bauersfeld M, Voß G. Neue wege im schnelligkeitstraining Philippka Verlag. 1992.

36. Rønnestad B. Acute effects of various whole-body vibration frequencies on lower-body power in trained and untrained subjectsi. J Strength Cond Res. 2009;23(7):1309-1315.

37. Güllich A, Schmidtbleicher D. struktur der kraftfähigkeiten und ihrer trainingsmethoden. Dtsch. Z. Sportmed. 1999;50(7+8):223-234. 